\title{
COORDINATION CHEMISTRY OF PERHALOGENATED CYCLOPENTADIENES AND ALKYNES, XII. SYNTHESIS AND MOLECULAR STRUCTURE OF \\ TRICARBONYL(TETRAKIS(TRIMETHYLSILYL)- CYCLOPENTADIENYL)MANGANESE
}

\author{
KARLHEINZ SÜNKEL* and JULIAN HOFMANN \\ Institut für Anorganische Chemie. Universität München. D-8000 Munich 2, Germany
}

(Received Feburary' 1, 1993) KEYWORDS: Manganese complexes, silylated cyclopentadienyl ligands,
tetrakis(trimethylsilyl)cyclopentadienyl complex

Cyclopentadienyl complexes with two or three $\mathrm{SiMe}_{3}$ substitutents have found widespread synthetic applications: $\pi$-complexes of the main group elements ${ }^{1}$ as well as of the f-group elements ${ }^{2}$ can be stabilized, hexane-soluble cationic complexes can be prepared ${ }^{3}$ and the stereochemical effects of these bulky substituents have been examined. ${ }^{4}$ A certainly interesting extension of this work to higher silylated complexes was, however, so far not feasible due to the lack of synthetic procedures for the preparation of these ligands. ${ }^{5}$ Only recently, we have shown that up to five $\mathrm{SiMe}_{2} \mathrm{H}$ substituents can be introduced into the cyclopentadienyl ligand of tricarbonyl( $\eta^{5}$-cyclopentadienyl)manganese ("cymantrene") starting from $\left[\mathrm{C}_{5} \mathrm{Br}_{5}\right] \mathrm{Mn}(\mathrm{CO})_{3}$ by a sequence of alternate bromine-lithium exchange reactions and electrophilic substitutions with $\mathrm{SiMe}_{2} \mathrm{HCl}^{6}$

$\left[\mathrm{C}_{5}\left(\mathrm{SiMe}_{2} \mathrm{H}\right)_{4} \mathrm{Br}\right] \mathrm{Mn}(\mathrm{CO})_{3}$, obtained in high yield by this procedure, reacts in $\mathrm{Et}_{2} \mathrm{O}$ at $-78^{\circ} \mathrm{C}$ with butyl lithium, followed by hydrolysis with a few drops of water, to give $\left[\mathrm{C}_{5}\left(\mathrm{SiMe}_{2} \mathrm{H}\right)_{4} \mathrm{H}\right] \mathrm{Mn}(\mathrm{CO})_{3}(1)$ in $85 \%$ isolated yield. In situ chlorination of the four Si-H functionalities can be achieved by stirring a benzene solution of 1 with five equivalents of $\mathrm{PdCl}_{2}$ at room temp., ${ }^{7}$ and careful addition of a 1.0 molar THF solution of $\mathrm{MeMgCl}$ yields $\left[\mathrm{C}_{5}\left(\mathrm{SiMe}_{3}\right)_{4} \mathrm{H}\right] \mathrm{Mn}(\mathrm{CO})_{3}(2)$ in about $50 \%$ isolated yield, (Scheme 1). This preparation is closely related to Sakurai's synthesis of $\left[\mathrm{C}_{6}\left(\mathrm{SiMe}_{3}\right)_{6}\right]$ from $\left[\mathrm{C}_{6}\left(\mathrm{SiMe}_{2} \mathrm{H}\right)_{6}\right]$, although the reagents and conditions applied in the benzene system do not work here. ${ }^{8}$

\footnotetext{
*Author for correspondence.
} 


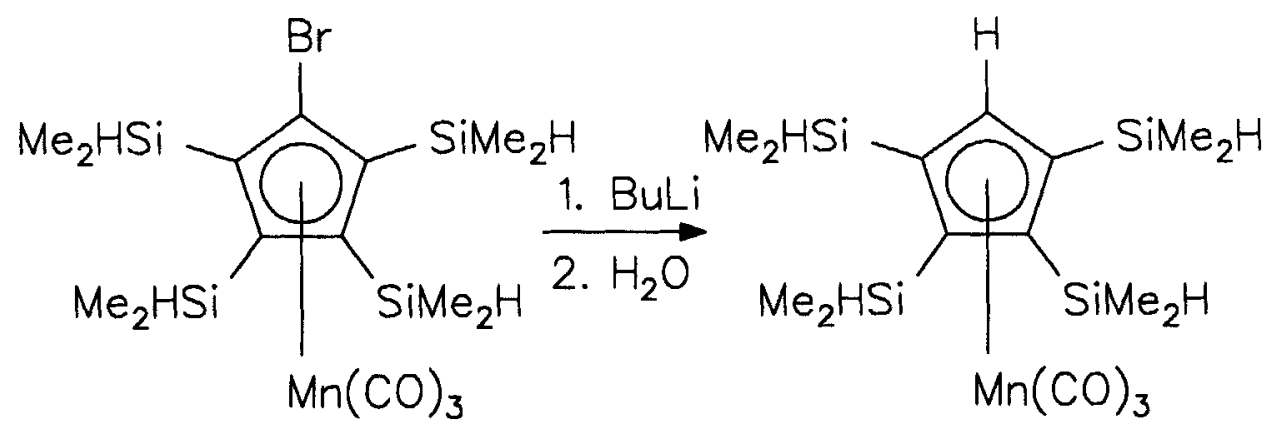
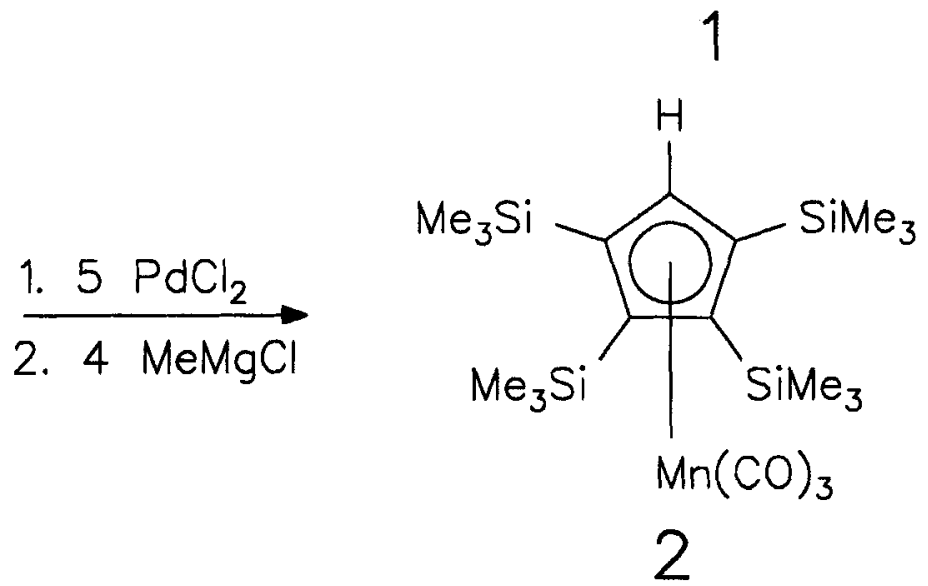

Scheme 1

At room temperature, $\left[\mathrm{C}_{5}\left(\mathrm{SiMe}_{3}\right)_{4} \mathrm{H}\right] \mathrm{Mn}(\mathrm{CO})_{3}$ shows only two signals for the $\mathrm{SiMe}_{3}$ groups in ${ }^{1} \mathrm{H}$ and the ${ }^{13} \mathrm{C}$ NMR spectra, ${ }^{\dagger}$ thus indicating the lack of substantial steric congestion in the complex. This result is rather surprising in the light of Okuda's observations with the $\left[\mathrm{C}_{5}\left(\mathrm{SiMe}_{3}\right)_{3} \mathrm{H}_{2}\right]$ system. To obtain more information, a crystal structure determination was performed (Fig. 1). ${ }^{\ddagger}$

The mean deviation in the cyclopentadienyl ring from the least-squares plane is only $0.0052 \AA$, but one of the silicon substitutents ( $\mathrm{Si} 3$ ) is shifted substantially away

\footnotetext{
${ }^{1} \mathrm{H}$ NMR $\left(270 \mathrm{MHz}, \mathrm{C}_{6} \mathrm{D}_{6}\right): \delta=0.303 \mathrm{~s}[18 \mathrm{H}], 0.400 \mathrm{~s}[18 \mathrm{H}], 5.426 \mathrm{~s}[1 \mathrm{H}]{ }^{13} \mathrm{C}$ NMR $(68 \mathrm{MHz}$, $\left.\mathrm{C}_{6} \mathrm{D}_{6}\right): \delta=2.75,4.48(\mathrm{SiC}), 98.4,109.5,111.1\left(C_{5} \mathrm{R}_{5}\right)$.

* Crystal data for 2: $\mathrm{C}_{20} \mathrm{H}_{37} \mathrm{MnO}_{3} \mathrm{Si}_{4}, M=492.8$, monoclinic, space group $P 2_{1} / n, a=11.458(5)$, $b=16.624(6) \AA, c=15.267(7) \AA, \beta=105.61(3)^{\circ}, V=2801(2) \AA^{3}, T=291 \mathrm{~K}, D_{c}=1.169 \mathrm{Mg} / \mathrm{m}^{3}$, $\mathrm{Z}=4, \mu\left(\mathrm{MoK}_{\alpha}\right)=0.636 \mathrm{~mm}^{-1}$. Nicolet $\mathrm{R} 3$ diffractometer, $\mathrm{MoK}_{\alpha}$ radiation, graphite monochromator, $\omega$-scan with variable scan speed, $2 \Theta$ range $4-40^{\circ}$. Structure solution and refinement with SHELXTL PLUS $4.1 / \mathrm{V}, R(F)=0.044, R_{n}=0.033$ for 2045 independent reflections $(|F| \geq 4 \sigma(|F|))$. Full lists of crystallographic data, atomic positions, thermal parameters, bondlengths and angles and observed and calculated structure factors are available from the authors upon request.
} 


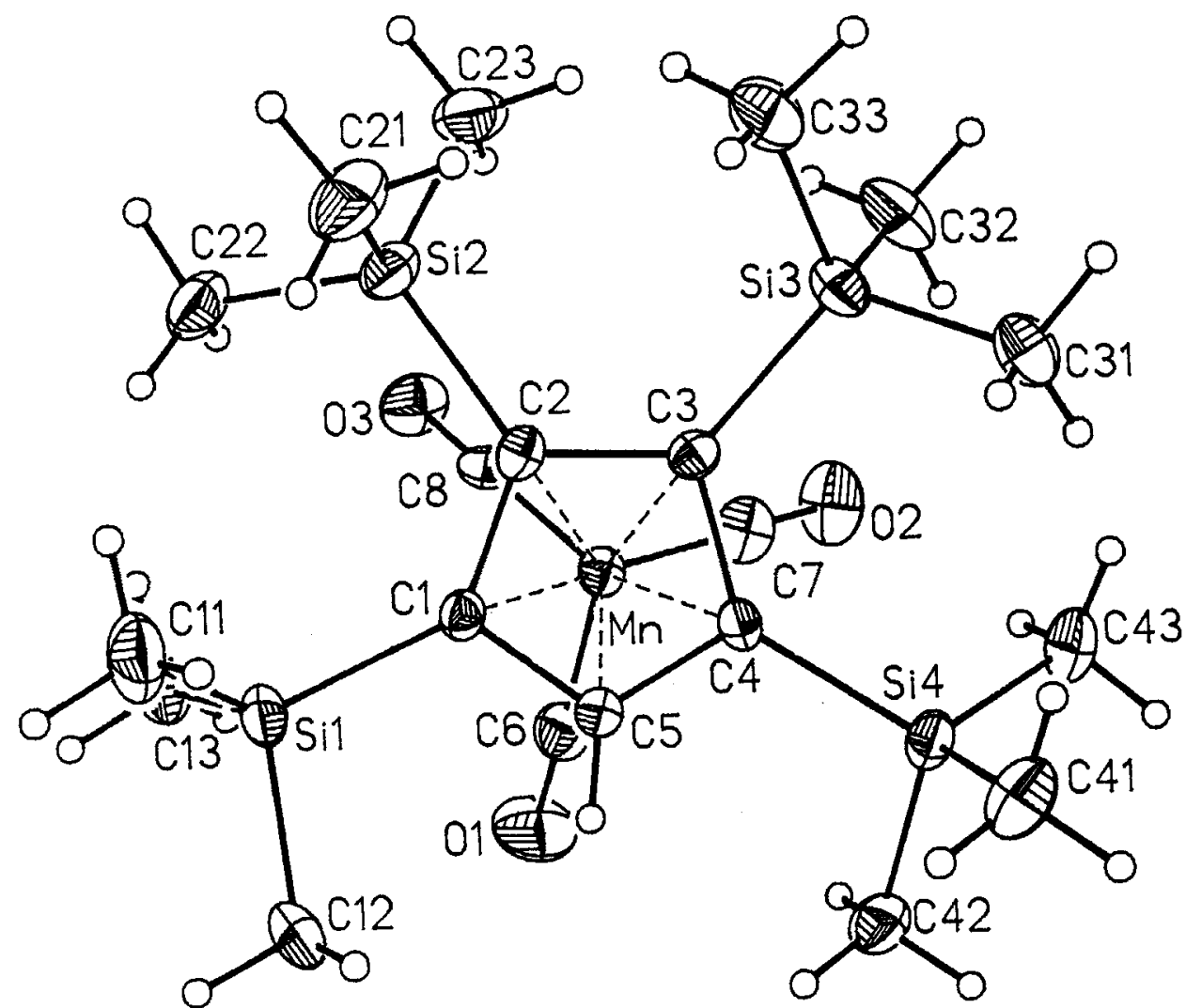

Figure 1 Molecular structure of 2 in the crystal. Thermal ellipsoids drawn at the $20 \%$ probability level.

from the $\mathrm{Mn}(\mathrm{CO})_{3}$ unit to the distal side of that plane $(0.2895 \AA)$, thus reducing the interaction with its two $\mathrm{SiMe}_{3}$ neighbours. The $\mathrm{C}-\mathrm{C}$ bond lengths range from 1.41 (1) to $1.48(1) \AA$ and are only slightly longer than in cymantrene complexes with no or smaller substitutents. The main difference (over $10^{\circ}$ ) from an idealized geometry is observed in the bond angles C2-C1-Sil and C3-C4-Si4. The two $\mathrm{SiMe}_{3}$ groups next to the unsubstituted ring carbon atom are "pushed" towards the sterically least demanding substituent, the $\mathrm{H}$-atom, thus avoiding too close a contact with the other two $\mathrm{SiMe}_{3}$ groups. This effect, together with the displacement of Si3 mentioned above, allows the cyclopentadienyl ring to remain planar and act further as a $\eta^{5}$ ligand.

\section{Acknowledgements}

We are greatly indebted to Prof. W. Beck for providing us with laboratory space. Generous financial support by the Deutsche Forschungsgemeinschaft and Fonds der Chemischen Industrie is gratefully acknowledged. 


\section{References}

1. P. Jutzi, Adv. Organomet. Chem., 26, 217 (1986).

2. P.C. Blake, M.F. Lappert, R.G. Taylor, J.L. Atwood and H. Zhang, Inorg. Chim. Acta, 139, 13 (1987); M.A. Edelman, M.F. Lappert, J.L. Atwood and H. Zhang, Inorg. Chim. Acta, 139, 185 (1987).

3. C.H. Winter, X-X. Zhou and M.J. Hey, Inorg. Chem., 31, 1808 (1992).

4. J. Okuda, Top. Curr. Chem., 160, 97 (1991).

5. P. Jutzi, J. Organomet. Chem., 400, 1 (1990).

6. K. Sünkel and J. Hofmann, Organometallics, 11, 3923 (1992).

7. L.P. Asatiani, D.S. Zurabishvili and L.M. Gverdtsiteli, J. Gen. Chem. USSR, 48, 2168 (1978); L.P. Asatiani, and A.A. El-Agami, J. Gen. Chem. USSR, 50, 1287 (1980).

8. H. Sakurai, K. Ebata; C. Kabuto and A. Sekiguchi, J. Amer. Chem. Soc, 112, 1799 (1990). 